\title{
3D Modeling of Combustion for DI-SI Engines
}

\author{
J.-M. Duclos ${ }^{1}$, M. Zolver ${ }^{1}$ and T. Baritaud ${ }^{1}$ \\ 1 Institut français du pétrole, 1 et 4, avenue de Bois-Préau, 92852 Rueil-M almaison Cedex - France \\ e-mail: j-marc.duclos@ifp.fr -marc.zolver@ifp.fr - thierry.baritaud@ifp.fr
}

\begin{abstract}
Résumé - Modélisation 3D de la combustion dans les moteurs à injection directe d'essence — L'injection directe d'essence (IDE) est un concept prometteur pour les moteurs à allumage commandé. La mise au point de ce type de moteur est néanmoins délicate, et le calcul 3D des chambres de combustion est un moyen d'aider à leur conception. Ceci nécessite cependant de disposer de modèles adaptés, à même de décrire le jet d'essence, son évaporation et la combustion du mélange créé.

Cet article présente un modèle ECFM qui permet de simuler la combustion dans les moteurs IDE, même en fonctionnement stratifié. Ce modèle est un développement du modèle flamme cohérente dans lequel des effets d'expansion thermique ont été introduits et qui a été couplé avec une description conditionnelle gaz frais/gaz brûlés des grandeurs thermodynamiques.
\end{abstract}

Une validation de ce modèle à l'aide de comparaison calcul-expérience sur trois points de fonctionnement du moteur GDI Mitsubishi a été effectuée.

Mots-clés : combustion, injection directe, modélisation 3D.

\begin{abstract}
D Modeling of Combustion in DI-SI Engines - Direct injection of gasoline is a promising concept to reduce fuel consumption of SI engines. The development of GDI engines is difficult and 3D CFD is a way to support its design. It requires models able to describe the spray and its evaporation and combustion.

This paper presents a model, the ECFM, that enables to compute combustion for stratified load in the GDI engines. This model is a development of the Coherent Flame Model which includes thermal expansion effects, and is coupled with a bunrt/unburnt gases condionnal thermodynamic properties description.

The model is validated by comparing measurements and computations on the GDI Mitsubishi engine in production.

Keywords: combustion, direct injection, 3D modeling.
\end{abstract}

\section{IN TRO DUCTIO N}

Direct injection of gasoline in the cylinder is a very promising concept to reduce fuel consumption of SI engines: the fuel stratification allows very lean combustion which reduces significantly the pumping work at low load.

For DI engines design, every parameter, like piston shape or injector inclination for example, has to be carefully adapted. CFD is a useful tool to understand the processes taking place in the combustion chamber and the correlation between parameters. It requires to model precisely each physical phenomenon occuring in the engine, from intake to combustion and pollutant generation.

This paper presents a combustion model integrated in the IFP 3D code KMB [12], a multiblock version of Kiva-II [1].
First, the hypothesis of the model are presented, then, the equations of the model are described. A comparison between computations and measurements on the GDI Mitsubishi engine concludes the work.

\section{MAJOR HYPOTHESIS OF THE MODEL}

\subsection{Flame Structure}

The main assumption made for this work is that the combustion of fuel occurs in a premixed regime, even for very lean or very rich combustion, and can be described with a flamelet type combustion model. Note that this hypothesis does not imply that all the chemical reactions occur under this way. 
The region of fuel consumption is supposed to be very thin and we assume that it separates unburnt from burnt gases. We also suppose that no fuel remains in the burnt gases. This last assumption can be easily justified: indeed the high temperature existing in the burnt gases leads to fuel molecules decomposition.

\subsection{Species Diffusion}

In the work presented here, all the species are supposed to have the same diffusivity. As the main contribution to species diffusion is "turbulent diffusion", which is a convection term, it is a fair assumption. The "turbulent" Schmidt number has no reason to differ from one specie to another.

To be consitent with the finite volume element approach, all the properties of the fluid are supposed to be locally homogeneous and isotropically distributed.

\subsection{Chemical Species Involved}

We suppose that the unburnt gases are only composed of fuel, molecular oxygen and nitrogen, carbon dioxyde and water. We could have assumed the existence of other components in the fresh gases, but it would have required one transport equation per added component, which is not cost effective regarding the overall description precision.

The burnt gases are supposed to be composed of molecular and atomic oxygen, nitrogen, and hydrogen, carbon monoxyde and dioxyde, $\mathrm{OH}$ and nitrogen monoxyde.

\subsection{Burnt Gases Chemical Reactions}

As it has been mentioned in Section 1.1, the fuel is not supposed to exist in the burnt gases, but chemical reactions may occur. All the reactions computed in the burnt gases are supposed to be bulk reactions. That means that no local structure of the reaction zone is taken into account and that these reactions are only function of the mean local quantites computed in the burnt gases. The reactions are solved using conditionned burnt gases properties.

Two kind of chemical reactions are simulated. The first set of reactions is supposed to be fast and the various component are supposed to be at equilibrium. We consider the following chemical system using constants proposed in [9]:

$$
\begin{array}{r}
\mathrm{N}_{2} \mathrm{D} 2 \mathrm{~N} \\
\mathrm{O}_{2} \mathrm{D} 2 \mathrm{O} \\
\mathrm{H}_{2} \mathrm{D} 2 \mathrm{H} \\
\mathrm{O}_{2}+\mathrm{H}_{2} \mathrm{D} 2 \mathrm{OH} \\
\mathrm{O}_{2}+2 \mathrm{H}_{2} \mathrm{O} \text { D } 4 \mathrm{OH} \\
\mathrm{O}_{2}+2 \mathrm{CO} \text { D } 2 \mathrm{CO}_{2}
\end{array}
$$

The second set is to compute NO formation and is an extended Zeldovitch kinetic mecanism (constants come from [8]):

$$
\begin{array}{r}
\mathrm{O}+\mathrm{N}_{2} \mathrm{D} \mathrm{N}+\mathrm{NO} \\
\mathrm{O}_{2}+\mathrm{N} \text { D O }+\mathrm{NO} \\
\mathrm{N}+\mathrm{OH} \mathrm{DH}+\mathrm{NO}
\end{array}
$$

For computational effectiveness, those two systems are sequentially solved, but with modified species balance for the kinetic set resolution that ensure that the same results would be obtained if the whole system was solved in a coupled way.

\subsection{Fuel Properties}

To approach real gasoline behaviour, especially for evaporation and combustion, a new fuel has been introduced in the KMB library. Its atomic formula is $\mathrm{C}_{7} \mathrm{H}_{13}$ and its thermochemical properties are choosen to be equivalent to typical RON95 unleaded gasoline.

\section{EQUATIONS OF THE MODEL}

\subsection{Fuel Consumption Rate}

\subsubsection{General Expression}

If $\tilde{Y}_{F}$ is the Favre averaged fuel mass fraction, the fuel conservation equation is written as:

$$
\frac{\partial \bar{\rho} \tilde{Y}_{F}}{\partial t}+\frac{\partial \bar{\rho} \tilde{U}_{i} \tilde{Y}_{F}}{\partial x_{i}}=\frac{\partial}{\partial x_{j}}\left(\frac{\mu_{\mathrm{t}}}{S c_{t}} \frac{\partial \tilde{Y}_{F}}{\partial x_{j}}\right)-\overline{\dot{\omega}}_{F}
$$

where:

$\bar{\rho} \quad$ is the mean density,

$\tilde{U}_{i}$ is the $i$ component of the mean fluid velocity, $\mu_{t}$ is the total viscosity, $S c_{t}$ is a turbulent Schmidt number, and

$\overline{\dot{\omega}}_{F}$ is the fuel consumption rate.

The combustion model we use is an improved version of the Coherent Flame Model, the ECFM (E stands for Extended).

As for the CFM, the fuel consumption rate might be written as:

$$
\overline{\dot{\omega}}_{F}=\bar{\rho}^{u} \tilde{Y}_{F}^{u} U_{L} \Sigma
$$

where:

$\bar{\rho}^{u}$ is the mean local density of the unburnt gases,

$\tilde{Y}_{F}^{u}$ is the mean fresh gaz fuel mass fraction,

$U_{L}$ is the speed that a laminar flame would have under the local thermochemical conditions undergoing by the turbulent flame, and

$\Sigma \quad$ is the flame surface density, that is, the local area of flame per unit of volume.

Thus to close our problem we need to know $\bar{\rho}^{u}, \tilde{Y}_{F}^{u}, U_{L}$ and $\Sigma$. 


\subsubsection{Laminar Flame Properties}

The laminar flame speed is estimated with the help of an experimental correlation proposed in [11] and [8]. It requires the knowledge of ambient pressure, local equivalence ratio, dillutant mass fraction and unburnt gases temperature.

The laminar flame thickness, which is also needed for the model, is obtained using [3] and requires the knowledge of laminar flame speed and burnt gases temperature.

Thus we need all the local conditioned burnt and unburnt gases properties in order to determine those two quantities.

\subsubsection{Flame Surface Density Transport Equation}

The flame surface density transport equation is very similar to the one used in [6]:

$$
\begin{aligned}
\frac{\partial \Sigma}{\partial \mathrm{d} t}+\frac{\partial \tilde{U}_{i} \Sigma}{\partial x_{i}}= & \frac{\partial}{\partial x_{j}}\left(\frac{\mu_{t}}{S c_{t}} \frac{\partial\left(\sum / \bar{\rho}\right)}{\partial x_{j}}\right) \\
& +\Phi(\Sigma)+K \Sigma-\beta U_{L} \frac{\Sigma^{2}}{1-\bar{c}}
\end{aligned}
$$

where:

$\Phi(\Sigma)$ is a source term due to the spark plug, including ignition and convection at the spark plug effects,

$\bar{c} \quad$ is the mean progress variable and

$K \quad$ is the total positive stretch. The mean progress variable is calculated with the following expression:

$$
\bar{c}=1-\frac{\bar{\rho} \tilde{Y}_{F}}{\bar{\rho}^{u} \tilde{Y}_{F}^{u}}
$$

There are two main contributions in $K$ : turbulence and the combined effets of curvature thermal and expansion. Assuming local isotropy of the flame surface density distribution, we have modelled it by:

$$
K=K t+\frac{2}{3} \frac{\bar{\rho}^{u}}{\bar{\rho}^{b}}(1-\bar{c}) \frac{\Sigma}{\bar{c}}+\frac{2}{3} \frac{\partial \tilde{U}_{i}}{\partial x_{i}}
$$

where:

$K_{t}$ is the turbulent stretch computed by the ITNFS model [10] and $\bar{\rho}^{b}$ is the density of the burnt gases. As in [6], a correction of $U_{L}$ and $K_{t}$ is introduced to model flame wall interaction effects.

\subsection{Ignition}

From the previous equations, one can notice that flame surface density has to be initialized at some point to start the computation of combustion. An analytical analysis has shown that the time at which flame surface density is initialised and the initialized quantity are critical.

Previous work [4, 12, 5] relied on the LI model. Some applications have shown that this model has difficulties to simulate some of the experimental trends, like pressure dependence. We choose to replace it by a correlation based on experimental results. This correlation depends on the local density and on the local laminar flame speed, but does not depend on the fuel or on the engine. The same correlation and the same model with the same constants are used for all the computations shown here. We have also used it for racing engines combustion computation at full load and higher engine speed. A burnt gases volume is also initialized to be consistent with the flame surface density initialization.

\subsection{Thermodynamic $Q$ uantities}

\subsubsection{General Consideration}

From the previous section, we see that we can close our model if we manage to know the local properties of burnt and unburnt gases. This section presents how these informations can be obtained locally in the whole computational domain.

\subsubsection{Species Concentrations Computation}

In every cell we compute two concentrations for every species: a concentration in the unburnt gases and a concentration in the burnt gases. To do so, we use a formalism already presented in [2] and [6]. Thus, two transport equations are introduced, one to represent the unburnt gases fuel concentration and the other for the unburnt gases oxygen concentration.

The main differences with [6] is that a source term due to the spray has to be added for the unburnt fuel mass fraction, and that a correction to the fuel source term has to be introduced in cells where combustion occurs to be consistant with the previous hypothesis.

With these two added equations and the hypothesis of local homogeneity and isotropy every concentration can be determined.

\subsubsection{Temperatures}

As in [2] or [6], a transport equation for the unburnt gases enthalpy is computed. But a source term due to evaporation of the liquid fuel in the cells where combustion occurs has also been introduced to be consistent with the hypothesis of local homogeneity.

From the unburnt gases enthalpy and the unburnt gases composition, the local unburnt gases temperature is computed. The burnt gases enthalpy, and consequently the burnt gases temperature, is deduced from the progress variable, the unburnt gases enthalpy and the mean enthalpy.

\section{TEST OF THE MODEL}

\subsection{Configuration}

The computed engines is the GDI Mitsubishi engine. Details of the computations can be found in [7]. The following table summarizes the operating conditions retained for the comparisons. 


\begin{tabular}{l|c|c|c}
\hline \multicolumn{1}{c|}{ Case } & 1 & 2 & 3 \\
\hline tr/min & 2000 & 2000 & 1500 \\
\hline BMEP (bar) & 2 & 3 & 3 \\
\hline F/A equ. ratio & 0.75 & 1 & 0.54 \\
\hline EGR (vol \%) & 0 & 5.7 & 18.5 \\
\hline Inj. tim. (CAD) & 331 & 333 & 75 \\
\hline Ign. tim. (CAD) & 36 & 26 & 24 \\
\hline
\end{tabular}
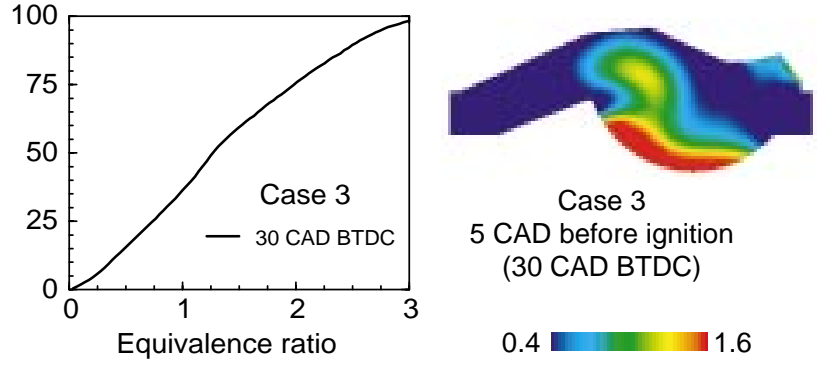

Case 3

5 CAD before ignition (30 CAD BTDC)

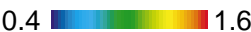

Figure 2

Equivalence ratio for the late injection case; cumulated histogram and distribution in the symmetry plane.

\subsection{Pressure Trace}

The computed and measured cylinder pressure are represented for the three cases on Figure 3. As it has been mentioned before, no coefficient has been changed from one case to another. load is rather homogeneous even if a rich spot remains at the top of the bowl for case 2 .

For case 3, it can be seen that before ignition, the fuel in the cylinder is distributed in a wide range of equivalence ratio, from very lean to very rich mixture.

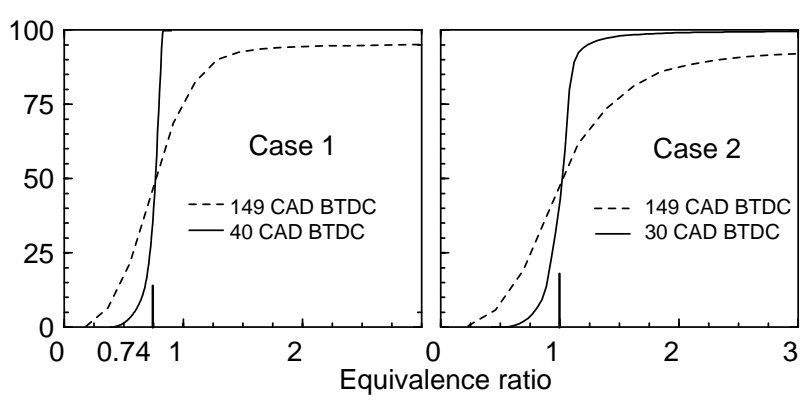

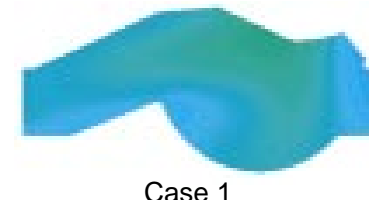

5 CAD before ignition (40 CAD BTDC)

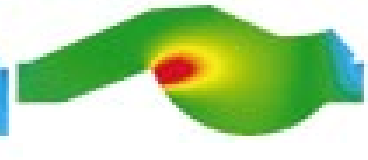

Case 2 5 CAD before ignition (30 CAD BTDC)

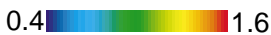

Figure 1

Equivalence ratio for the two early injection cases; cumulated histogram and distribution in the symmetry plane.

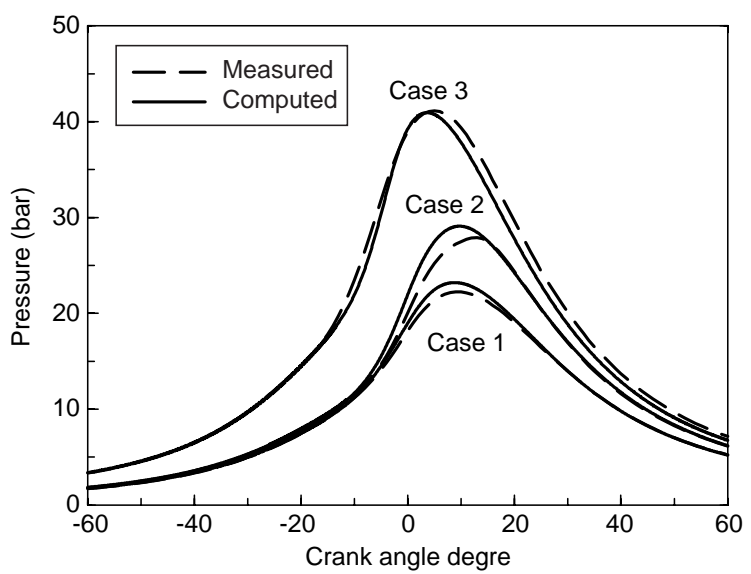

Figure 3

Comparison between computed and measured cylinder pressure for the three cases.

The overall agreement is rather good, even if the model slightly overpredicts the combustion speed. The delay is also overpredicted by the model in the stratified case, but it might be due to a too coarse of the fuel distribution given by the spray modeling.

\subsection{Flame Propagation}

Figure 4 represents the flame surface density in the symmetry plane of the engine at three different crank angle degrees. 


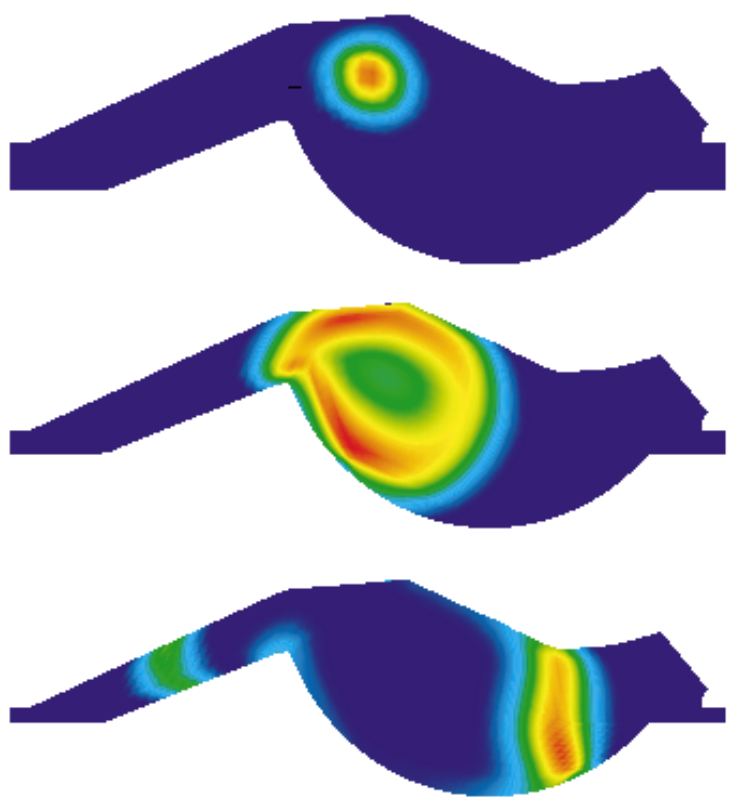

Figure 4

Flame surface density 20 CAD BTDC, 10 CAD BTDC and at TDC for the case 3 in the symmetry plane of the engine.

The picture at the top of this figure shows the flame kernel soon after the flame was initialised in the computational domain. Then it propagates fast in the middle of the chamber due to high equivalence ratio and expansion. It slows down when approaching the cylinder walls due to lean mixture.

\subsection{NO (N ITRO GEN OXIDE)}

The comparison between measured and computed $\mathrm{NO}_{\mathrm{x}}$ emissions are summarized in the following table:

\begin{tabular}{c|c|c}
\hline & Comp. & Exp. \\
\hline Case 1 & 2450 & 1450 \\
\hline Case 2 & 1650 & 1750 \\
\hline Case 3 & 550 & 670 \\
\hline
\end{tabular}

For case 2 and case 3 the agreement between computation and experiment is rather good. The $\mathrm{NO}_{\mathrm{x}}$ production is slightly underpredicted by the computation in case 3 , but it might be due to the under prediction of the IMEP. The differences between computed and measured $\mathrm{NO}_{\mathrm{x}}$ emission for case 2 have not been explained yet and further experimental and computational work would be needed to determine wether this difference is due to the kinetic constants used or to a great sensitivity of $\mathrm{NO}_{\mathrm{x}}$ emissions to the maximum cylinder pressure for lean operating conditions.

Figure 5 shows an interesting behaviour of NO distribution in the cylinder. The location of the maximum NO concentration is not the location of the maximum
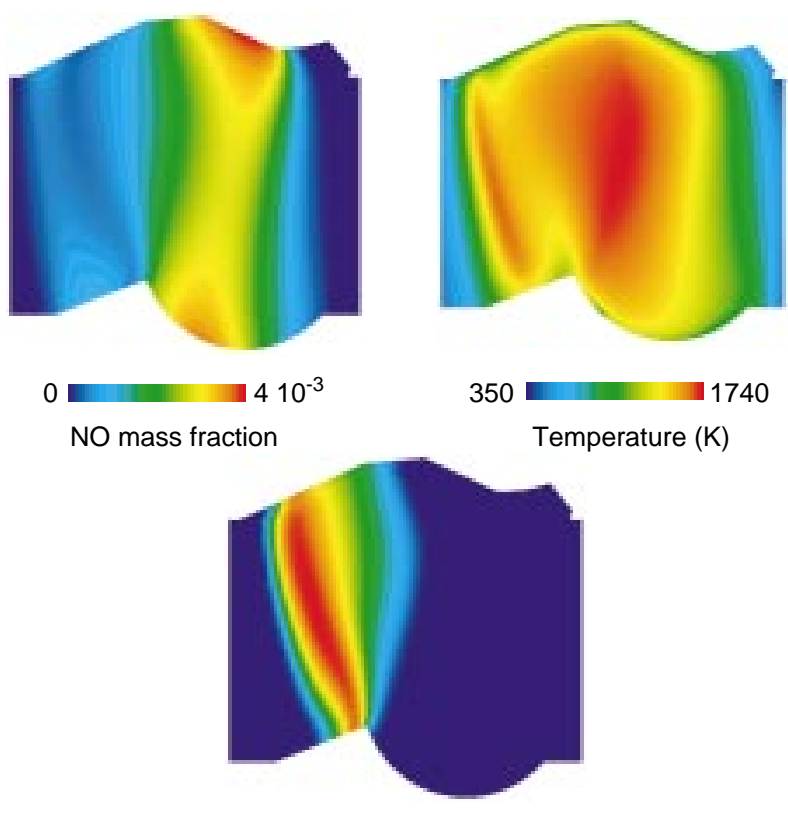

0

CO mass fraction

Figure 5

NO mass fraction, $\mathrm{CO}$ mass fraction and temperature $90 \mathrm{CAD}$ ATDC for case 3 in the symmetry plane of the engine.

temperature. This can be explained by the $\mathrm{CO}$ concentration distribution. The maximum temperature is situated where $\mathrm{CO}$ concentration is rather high, that is where the oxygen concentration is very low. At those locations, NO is reduced by the product, and no NO appears despite the high temperature.

\section{CONCLUSIONS}

A model has been developed to describe combustion in DI-SI engines. This model is fully coupled with the spray model and enables stratified combustion modeling including EGR effects, and NO formation. The model relies on a conditional unburnt/burnt description of the thermochemical properties of the gases. The overall agreement between computation and experiment is rather good, even for NO prediction, and the developed model can already be used to help understanding DI-SI engine behaviours and to improve their design.

Future work will focus on small scale heterogeneity modeling, refined post-flame chemistry (including soot formation), laminar flame speed prediction (specially for very lean or very rich combustion) and on ignition description improvements. 


\section{REFERENCES}

1 Amsden A., O'Rourke P., and Butler T. (1989) Kiva-II, A Computer Program for Chemically Reactive Flows with Sprays. Technical report La-11560-MS, Los Alamos Nat. Lab., Los Alamos.

2 Baritaud T., Duclos J.M., and Fusco A. (1996) Modeling Turbulent Combustion and Pollutant Formation in Stratified Charge Si Engines. In 26th Symposium (International) On Combustion, The Combustion Institute, 2627-2635.

3 Blint R. (1986) The Relationship of the Laminar Flame width to Flame Speed. Combust. Sci. Technol., 49, 79-92.

4 Boudier P., Henriot S., Poinsot T., and Baritaud T. (1992) A Model for Turbulent Flame Ignition and Propagation in Piston Engines. In 24th Symposium (International) On Combustion, The Combustion Institute.

5 Delhaye B. and Cousyn B. (1996) Computation of Flow and Combustion in Spark Ignition Engine and Comparison with Experiment. SAE No. 961960.

6 Duclos J.M., Bruneaux G., and Baritaud T. (1996) 3D Modeling of Combustion and Pollutants in a 4-Valve SI Engine, Effect of Fuel and Residuals Distribution and Spark Location. SAE No. 961964.
7 Duclos J.M. and Zolver M. (1998) 3D Modeling of Intake, Injection and Combustion in a DI-SI Engine under Homogeneous and Stratified Operating Conditions. In Comodia 98, 335-340.

8 Heywood J. (1988) Internal Combustion Engine Fundamentals, Mc Graw Hill.

9 Meintjes K. and Morgan A. (1987) Element Variables and the Solution of Complex Chemical Equilibrium Problems. General Motors Research Publication GMR-5827, 1987.

10 C. Meneveau And T. Poinsot. Stretching And Quenching Of Flamelets In Premixed Turbulent Combustion. Combust. Flame, 86, 311-332.

11 Metghalchi M. and Keck J. (1982) Burning Velocities of Mixtures of Air with Methanol, Isooctane, and Indolene at high Pressure and Temperature. Combust. Flame, 48, 191-210.

12 Torres A. and Henriot S. (1994) 3D Modeling of Combustion in Lean Burn Four-Valve Engines: Influence of Intake Configuration. in Comodia 94, 151-156.

Final manuscript received in March 1999 